\title{
ESTIMATION OF SLOW- AND FAST-CYCLING SOIL ORGANIC CARBON POOLS FROM 6N HCI HYDROLYSIS
}

\author{
S. W. LEAVITT, ${ }^{1}$ R. F. FOLLETT ${ }^{2}$ and E. A. PAUL ${ }^{3}$
}

\begin{abstract}
Acid hydrolysis is used to fractionate the soil organic carbon pool into relatively slow- and fast-cycling compartments on soils from Arizona, the Great Plains states and Michigan collected for carbon isotope tracer studies related to soil carbon sequestration, for studies of shifts in $\mathrm{C}_{3} / \mathrm{C}_{4}$ vegetation, and for "pre-bomb" soil-carbon inventories. Prior to hydrolysis, soil samples are first treated with cold $0.5-1 \mathrm{~N} \mathrm{HCl}$ to remove soil carbonates if necessary. Samples are then dispersed in a concentrated $\mathrm{NaCl}$ solution $\left(\rho-1.2 \mathrm{~g} \mathrm{~cm}^{-3}\right)$ and floated plant fragments are skimmed off the surface. After rinsing and drying, all remaining recognizable plant fragments are picked from the soil under $20 \times$ magnification. Plant-free soils, and hot, $6 \mathrm{~N}$ $\mathrm{HCl}$ acid-hydrolysis residue and hydrolyzate fractions are analyzed for carbon content, $8^{13} \mathrm{C}$ and ${ }^{14} \mathrm{C}$ age, and the carbon distribution is verified within $1-2 \%$ by stable-carbon isotope mass balance. On average, the recalcitrant residue fraction is 1800 yr older and $2.6 \%$ more ${ }^{13} \mathrm{C}$-depleted than total soil organic carbon. A test of hydrolysis with fresh plant fragments produced as much as $\mathbf{7 1 - 7 6 \%}$ in the acid-hydrolysis residue pool. Thus, if plant fragments are not largely removed prior to hydrolysis, the residue fraction may date much younger than it actually is.
\end{abstract}

\section{INTRODUCTION}

An understanding of soil dynamics and carbon cycling in soils requires estimating the types and sizes of soil carbon pools as well as the mean residence times in each. For modeling purposes, the number of soil organic carbon pools is often simplified. For example, Parton et al. (1987) incorporated five organic carbon pools in their model including an "active" fraction of microbial products and rapidly cycling soil organic matter (SOM) (1-5 yr turnover time), a slowly cycling SOM pool (25 yr), a passive pool (200-1500 yr), a plant residue structural pool (1-5 yr) and a plant residue metabolic pool (0.1-1 yr). Schimel et al. (1993) modeled a rapid-cycling microbial matter pool with residence time of $<1$ to $>4 \mathrm{yr}$, a "passive" carbon pool with residence time of 600 to $>5000 \mathrm{yr}$, and detritus and "slow" organic carbon pools whose residence times are intermediate between the fastand slow-cycling pools. Schimel et al. (1993) found the organic carbon residence time of each compartment to be correlated to the temperature, and the distribution of carbon among the compartments to be influenced by texture.

Researchers have attempted to define such organic carbon pools by means of physical and chemical methods. Anderson and Paul (1984) determined ${ }^{14} \mathrm{C}$ activity on coarse and fine, silt and clay fractions, with the fine silt and coarse clay fractions containing the oldest carbon and the fine clay fraction somewhat younger, suggesting the fine clay is a site of short- to medium-term protection of labile humic compounds. Cambardella and Elliott (1992) used dispersion and collection on a $53 \mu \mathrm{m}$ sieve to isolate a "particulate organic matter" (POM) fraction in grassland soils that slowly cycled over a time frame of several decades. This cycling was much faster than the mineral-associated organic matter fraction, and Cambardella and Elliott (1992) suggested this fraction constitutes most SOM lost initially from cultivation of grassland soils.

Campbell et al. (1967) found distinctly different ages among chemical fractions with non-hydrolyzable, total humic acid and humin fractions being older than bulk unfractionated soil organic carbon, and fulvic acid generally being younger than the bulk value. Nissenbaum and Schallinger (1974) also isolated "traditional" organic fractions within the $\mathrm{NaOH}$ soluble portion of soil organic carbon in a variety of soil types by means of acetone and ethanol extraction. These included humic acid, ful-

\footnotetext{
${ }^{1}$ Laboratory of Tree-Ring Research, The University of Arizona, Tucson, Arizona 85721 USA

${ }^{2}$ USDA-ARS-NPA, Soil, Plant, Nutrient Research/NRRC, 301 S. Howes, Fort Collins, Colorado 80521 USA

${ }^{3}$ Department of Soil and Crop Sciences, Michigan State University, East Lansing, Michigan 48824 USA
} 
vic acid and their components, and they found humic acid more ${ }^{13} \mathrm{C}$-depleted than the fulvic acid (ca. 0.6-1.2\%). Martel and Paul (1974) opted for the products of acid hydrolysis rather than the traditional fractions because earlier incubation experimental work with labeled ${ }^{14} \mathrm{C}$ showed only small differences of label concentration in the traditional fractions, but a much greater range of labeled ${ }^{14} \mathrm{C}$ activities in the hydrolyzed fractions. They found that $\mathrm{HCl}$ hydrolysis effectively dissolves the young constituent carbon compounds, leaving older resistant molecules in the residue, and was thus a useful technique to explore soil organic carbon stability in nature. Scharpenseel and Schiffmann (1977) and Stout et al. (1981) also promoted acid hydrolysis as a standard procedure for soil fractionation. Trumbore (1993) combined density separation with acid hydrolysis, and found the latter to be fairly effective in isolating old carbon from certain soils (temperate), but with some "bomb" carbon making its way into the residue fraction since 1959. However, the acid hydrolysis procedure was totally ineffective in isolating old carbon from tropical soils. Trumbore (1993) suggested that acid hydrolysis may solubilize some refractory carbon, or permit exchange of young for old carbon on functional groups of the refractory organic matter. Scharpenseel (1977) had previously determined that acid hydrolysis residues may contain cellulose, but that increasingly greater ages were obtained with each of 8 successive $6 \mathrm{~N} \mathrm{HCl}$ hydrolyses.

Since 1991, we have been routinely using acid hydrolysis in our ${ }^{14} \mathrm{C}$ and $\delta^{13} \mathrm{C}$ analysis to differentiate labile and recalcitrant soil organic carbon fractions. We present here a summary of the characteristics of these fractions as applied to soils from Arizona, Michigan and the Great Plains states. We also consider the question of hydrolysis of fresh plant matter as it relates to partitioning between the hydrolyzate and residue fractions of acid hydrolysis.

\section{METHODS}

Surface soil samples were collected from all sites at depths of $0-10,0-15$ or $0-30 \mathrm{~cm}$. For several sites, samples were variously taken at greater depths in the profile (from 10-20 to up to 90-120 cm). The Arizona (Entisol) soil samples from Maricopa County, Arizona, were collected in conjunction with the "Free-Air Carbon Dioxide Enrichment" (FACE) experiment with cotton in 1991 from control plots that received ambient air $\mathrm{CO}_{2}$, and from enriched plots that received $550 \mathrm{ppm} \mathrm{CO}_{2}$ (Leavitt et al. 1994). Great Plains (dominantly Mollisol) soils were collected in Kansas, Nebraska, Colorado, North Dakota and Texas, and included both cultivated and uncultivated soils as well as some pre"bomb" samples. For the Great Plains soils, exact locations, ages, variations of ${ }^{14} \mathrm{C}$ and $\delta^{13} \mathrm{C}$ with depth and implications of these results to the vegetational history of the area and to modern processes will be reported in detail elsewhere (Paul et al. ms.; Follett et al. ms.). The Michigan (Alfisol) soils were collected at the Kellogg Long-Term Ecological Research (LTER) site near Kalamazoo. The grain size and soil taxonomic classification are detailed in Paul et al. (ms.) with soils ranging in clay content from $c a .11$ to $34 \%$, whereas organic carbon contents are in the range of $c a .0 .4$ to $3 \%$ (Follett et al. ms.).

Soil samples were first sieved at $1 \mathrm{~mm}$ to remove large plant fragments and pebbles, and a subsample of $50-100 \mathrm{~g}$ was acidified with $0.5-1 \mathrm{~N} \mathrm{HCl}$ to remove the carbonate fraction found in most of the samples. The samples were then immersed in a concentrated $\mathrm{NaCl}$ solution $\left(\rho \sim 1.2 \mathrm{~g} \mathrm{~cm}^{-3}\right)$ and stirred. Following settling of the heavier solids, floating plant fragments were skimmed from the surface. This was repeated until the samples no longer had a component that floated, after which the soils were rinsed free of salt, dried and pulverized with a mortar and pestle.

Between 1 and $5 \mathrm{~g}$ of these processed soil samples were then further picked free of recognizable plant and root fragments under a binocular microscope at 20x. Organic carbon content and $\delta^{13} \mathrm{C}$ 
were determined after combustion of $0.10-0.25 \mathrm{~g}$ subsamples of these soil samples in quartz tubes at $900^{\circ} \mathrm{C}$ in the presence of copper oxide, silver foil and copper turnings (Boutton 1991). Carbon yield was determined manometrically from the $\mathrm{CO}_{2}$ combustion product, and $\mathrm{CO}_{2}$ was analyzed primarily with a VG Micromass $602 \mathrm{C}$ isotope ratio mass spectrometer to determine $\delta^{13} \mathrm{C}$ (some analyses were performed with a Finnigan MAT Delta-S mass spectrometer). Isotope ratio mass spectrometer precision is $c a . \pm 0.05 \%$ for repeated analysis of the same $\mathrm{CO}_{2}$ gas. Seven separate combustions and analyses of subsamples of one FACE soil sample produced a mean ${ }^{13} \mathrm{C}$ of $-23.40 \%$ with respect to PDB ( $s=0.25 \%$ ), and a manometrically determined, mean organic carbon content of $0.60 \%$ ( $\mathrm{s}=0.03 \%$ ). Seven more recent runs with another soil standard gave a $\delta^{13} \mathrm{C}$ precision $( \pm 1 \sigma)$ of $0.33 \%$ and a carbon content precision $( \pm 1 \sigma)$ of $\pm 0.06 \%$. Acid hydrolysis was performed on most of the soils that were free of carbonates and plant fragments. One to $3 \mathrm{~g}$ of soil were placed into a $500-\mathrm{ml}$ round-bottom flask with $c a .50 \mathrm{ml}$ of $6 \mathrm{~N} \mathrm{HCl}$. With a water-cooled condenser installed above the flask, the mixture was heated to boiling with an electric heating mantle for $c a .18 \mathrm{~h}$. The soluble (hydrolyzate or "supernatant") fraction was recovered following filtering and heating to evaporate the liquid. The resistant ("residue") fraction was obtained by rinsing the material collected on the filter with deionized water and then drying. For samples for which $\delta^{13} \mathrm{C}$ was measured on both the acid-hydrolysis residue and hydrolyzate fractions, an isotope mass balance was calculated with the carbon yields to verify the procedure. On average, the calculated mass-balance total carbon $\delta^{13} \mathrm{C}$ was within $1-2 \%$ of the measured $\delta^{13} \mathrm{C}$ (mean difference between mass-balance and measured $\delta^{13} \mathrm{C}$ was $-0.31 \%$, $\mathrm{s}=0.91 \%$, $\mathrm{n}=50$ ). The results reported herein are all processed and analyzed in the above manner at the Laboratory of Tree-Ring Research/The University of Arizona, but there is a small bias (1-2\%) relative to measurements of the same standards at USDA-ARS/Ft. Collins and the Department of Crop and Soil Sciences/Michigan State University. We are in the process of resolving the differences by systematic examination of the procedures.

Processed soils and hydrolysis soil fractions were also combusted to $\mathrm{CO}_{2}$ by the above method for tandem accelerator mass spectrometer (TAMS) ${ }^{14} \mathrm{C}$ analysis at the NSF-Arizona Accelerator Facility. The $\mathrm{CO}_{2}$ samples were reduced to $\mathrm{CO}$ on hot zinc, and then to graphite on hot iron (Slota et al. 1987). Accelerator measurements of ${ }^{14} \mathrm{C}$ activity of the graphite were calculated as percent modern carbon (pMC) with a $\delta^{13} \mathrm{C}$ correction for fractionation.

The hydrolysis test of plant fragments employed two samples of FACE cotton field stubble collected 26 April 1992, one from an enriched $\mathrm{CO}_{2}$ plot and the other from its paired control plot. The samples were ground to 20 mesh and then hydrolyzed with boiling $6 \mathrm{~N} \mathrm{HCl}$ for $18 \mathrm{~h}$. Hydrolyzate and residue were separated by filtering, rinsing the residue and heating the hydrolyzate to dryness. Carbon distribution was calculated from the recovered dry masses and manometrically determined carbon contents.

\section{RESULTS AND DISCUSSION}

We analyzed 65 soil samples: 2 from Michigan, 12 from Arizona and 51 from the Great Plains. Within this total, samples from different depths of the same profile are considered as separate samples. Of this set of samples, all but four had a ${ }^{14} \mathrm{C}$ measurement on at least one soil fraction. The 37 surface soil samples represent depths ranging from $0-10 \mathrm{~cm}$ to $0-30 \mathrm{~cm}$, depending on the site and requirements of other companion experiments for soil sampling. Figure $1 \mathrm{~A}$ shows the distribution of ${ }^{14} \mathrm{C}$ ages among the total carbon and acid-hydrolysis residue fraction of the surface soils. The ${ }^{14} \mathrm{C}$ activity of the total organic carbon (after floating and picking plant fragments) was "modern" ("post-bomb") for eight of the samples, the highest being 118.73 $\pm 0.66 \mathrm{pMC}$ (possible tracer contamination). Three others, including one subsurface soil, had activities $>500 \mathrm{pMC}$, and were clearly 

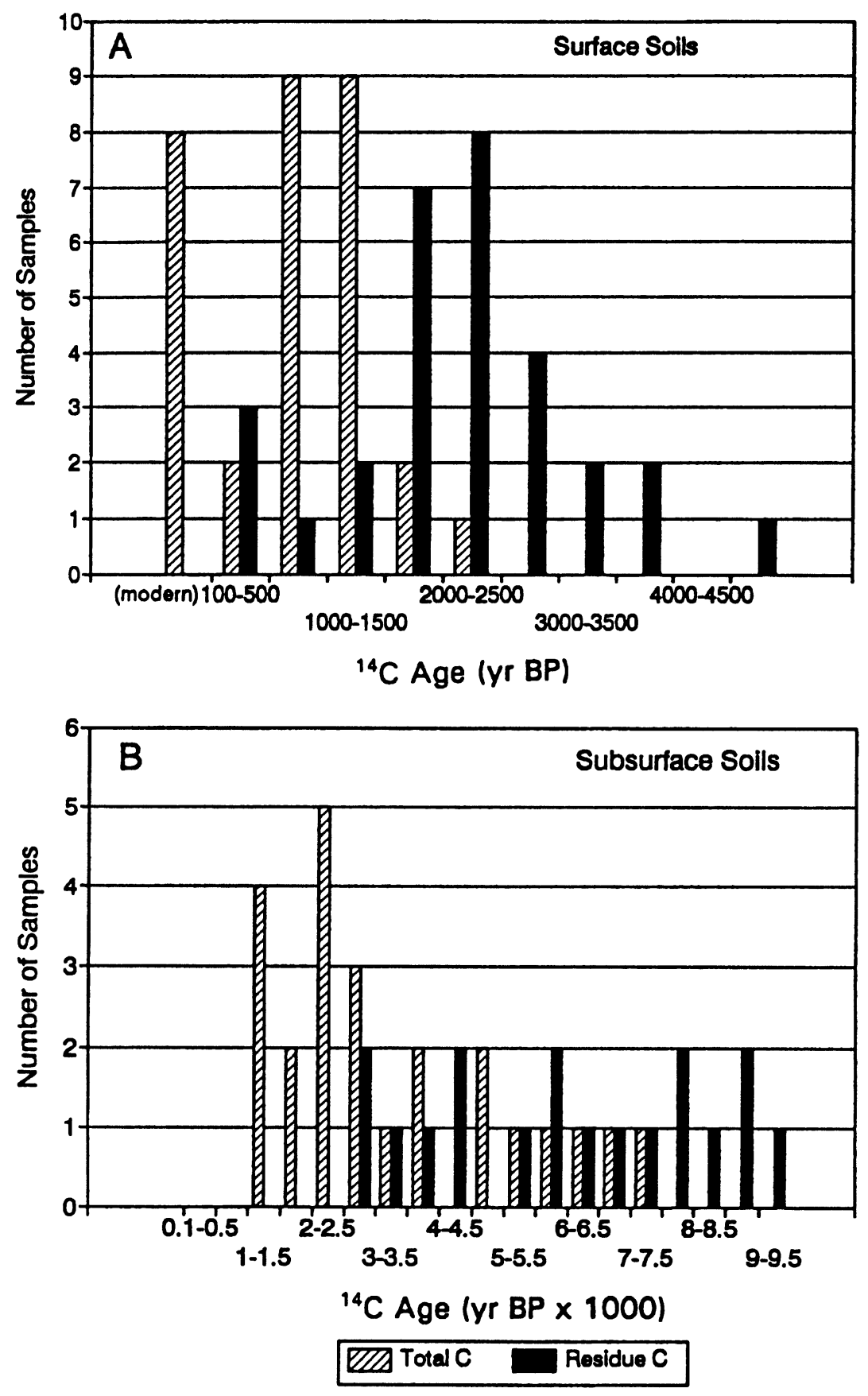

Fig. 1. Distribution of ${ }^{14} \mathrm{C}$ ages among soil organic carbon fractions of surface $(A)$ and subsurface (B) soils. $\rrbracket=$ total carbon; $\square=$ acid-hydrolysis residue. 
contaminated with tracer ${ }^{14} \mathrm{C}$. This contamination, however, was restricted to 4 soils, and was not found in $\mathbf{4 0}$ or more subsequent samples. We thus believe the tracer contamination did not derive from The University of Arizona laboratories. The lowest ${ }^{14} \mathrm{C}$ activity of surface-soil total organic carbon was $77.22 \pm 0.49 \mathrm{pMC}(2075 \pm 50 \mathrm{BP})$. In all cases, the ${ }^{14} \mathrm{C}$ activity of the acid-hydrolysis residue fraction was older than the total carbon, with activity ranging from $97.90 \pm 0.75 \mathrm{pMC}(170$ $\pm 60 \mathrm{BP})$ to $54.33 \pm 0.40 \mathrm{pMC}(4900 \pm 60)$. The ${ }^{14} \mathrm{C}$ activities of the acid-hydrolysis hydrolyzate fraction were measured on only six surface soils, and they ranged from 107.7 to $93.3 \mathrm{pMC}$ (modern to $340 \pm 60 \mathrm{BP}$ ).

For the subsurface soils (Fig. 1B), ${ }^{14} \mathrm{C}$ activity of the total organic carbon ranged from $85.99 \pm 0.57$ pMC (1215 $\pm 55 \mathrm{BP})$ to $39.48 \pm 0.33(7465 \pm 65)$. The ${ }^{14} \mathrm{C}$ activity of the acid-hydrolysis residue fraction of these soils ranged from $70.15 \pm 0.54 \mathrm{pMC}(2850 \pm 60 \mathrm{BP})$ to $30.75 \pm 0.49(9475 \pm 125)$. Table 1 summarizes the average differences in ${ }^{14} \mathrm{C}$ between pairs of total organic carbon and the acid-residue fraction carbon. For all soils, the average activity difference is $16.0 \mathrm{pMC}$ and the average age difference is $1804 \mathrm{yr}$. The average differences in ${ }^{14} \mathrm{C}$ activity for surface and subsurface soils calculated separately are 16.5 and $15.4 \mathrm{pMC}$, respectively. However, the average age difference between these fractions for surface and subsurface soils is 1485 and $2282 \mathrm{yr}$, respectively. The greater age difference for the subsurface relative to surface soils, despite their similarity of activity difference, is simply a function of their lower overall ${ }^{14} \mathrm{C}$ activity combined with the exponential nature of the ${ }^{14} \mathrm{C}$ dating equation.

TABLE 1. Summary of Paired Differences in $8^{13} \mathrm{C}$ and ${ }^{14} \mathrm{C}$ Activity of Soil Organic Carbon Fractions*

\begin{tabular}{lccc}
\hline Fraction & Surface soils & Subsurface soils & All soils \\
\hline$\delta^{13} \mathrm{C}_{\mathrm{PDB}} \% \circ$ (total-residue) & $1.77 \pm 0.91(30)$ & $4.09 \pm 2.05(17)$ & $2.61 \pm 1.80(47)$ \\
$\delta^{13} \mathrm{C}_{\mathrm{PDB}} \% 0$ (total-hydrolyzate) & $2.14 \pm 1.16(29)$ & $-1.53 \pm 0.93(15)$ & $-1.93 \pm 1.12(44)$ \\
$\delta^{13} \mathrm{C}_{\mathrm{PDB}} \% 0$ (residue-hydrolyzate) & $-3.89 \pm 1.80(29)$ & $-5.76 \pm 1.78(15)$ & $-4.53 \pm 1.99(44)$ \\
${ }^{14} \mathrm{C}$ activity pMC (total-residue) & $16.5 \pm 9.3(27)$ & $15.4 \pm 7.7(18)$ & $16.0 \pm 8.6(45)$ \\
${ }^{14} \mathrm{C}$ age yr BP (total-residue) & $-1485 \pm 877(27)$ & $-2282 \pm 1191(18)$ & $-1804 \pm 1077(45)$ \\
\hline
\end{tabular}

*Values represent the mean \pm 1 standard deviation (number of cases in parenthesis).

For $\delta^{13} \mathrm{C}$, with only three exceptions in all the soils, the acid-hydrolysis residue was the most ${ }^{13} \mathrm{C}$ depleted, the hydrolyzate was the most ${ }^{13} \mathrm{C}$-enriched. On average, the $\delta^{13} \mathrm{C}$ of all total organic carbon, acid-hydrolysis residue and hydrolyzate fractions was $-19.9,-22.5$ and $-18.2 \%$, respectively. However, the within-fraction variability is quite high $\left(e . g ., \delta^{13} \mathrm{C}\right.$ of total carbon varied from -15.2 to $-27.0 \%$ ) because of the variety of soil types and developmental histories; standard deviations are $2.5(\mathrm{n}=64), 2.2(\mathrm{n}=47)$ and $2.8 \%(\mathrm{n}=44)$, respectively. When the surface and subsurface soils are considered separately (Fig. 2), the three fractions are $-20.7 \pm 2.1(n=37),-22.5 \pm 2.0(n=30)$ and $-18.7 \pm 2.9 \% 0(n=29)$, and $-18.7 \pm 2.7(n=27),-22.5 \pm 2.6(n=17)$ and $-17.3 \pm 2.2 \% 0(n=15)$, respectively. The similarity of acid-hydrolysis residue and hydrolyzate $\delta^{13} \mathrm{C}$ values, but the difference (ca. 2\%o) in total organic carbon $\delta^{13} \mathrm{C}$ between these depths, is a consequence of the large difference in average distribution of carbon at these two depths. For the surface soils, $55.5 \pm 8.6 \%$ of the carbon is in the residue and $45.5 \pm 8.6 \%(n=30)$ is in the hydrolyzate, whereas for the subsurface soils, there is an average of $44.3 \pm 9.5 \%$ in the residue and $55.7 \pm 9.5 \%(n=18)$ in the hydrolyzate. Given the greater age of the subsurface soils, these relations may reflect a shift in isotopic values during the soil-forming process, by which soils may become $1-3 \%$ more ${ }^{13} \mathrm{C}$-enriched by microbial decomposition (Dzurec et al. 1985; Bertram 1985; Becker-Heidmann and Scharpenseel 1986). However, because the fraction of carbon from acid-hydrolysis residue is on average less than that from the 

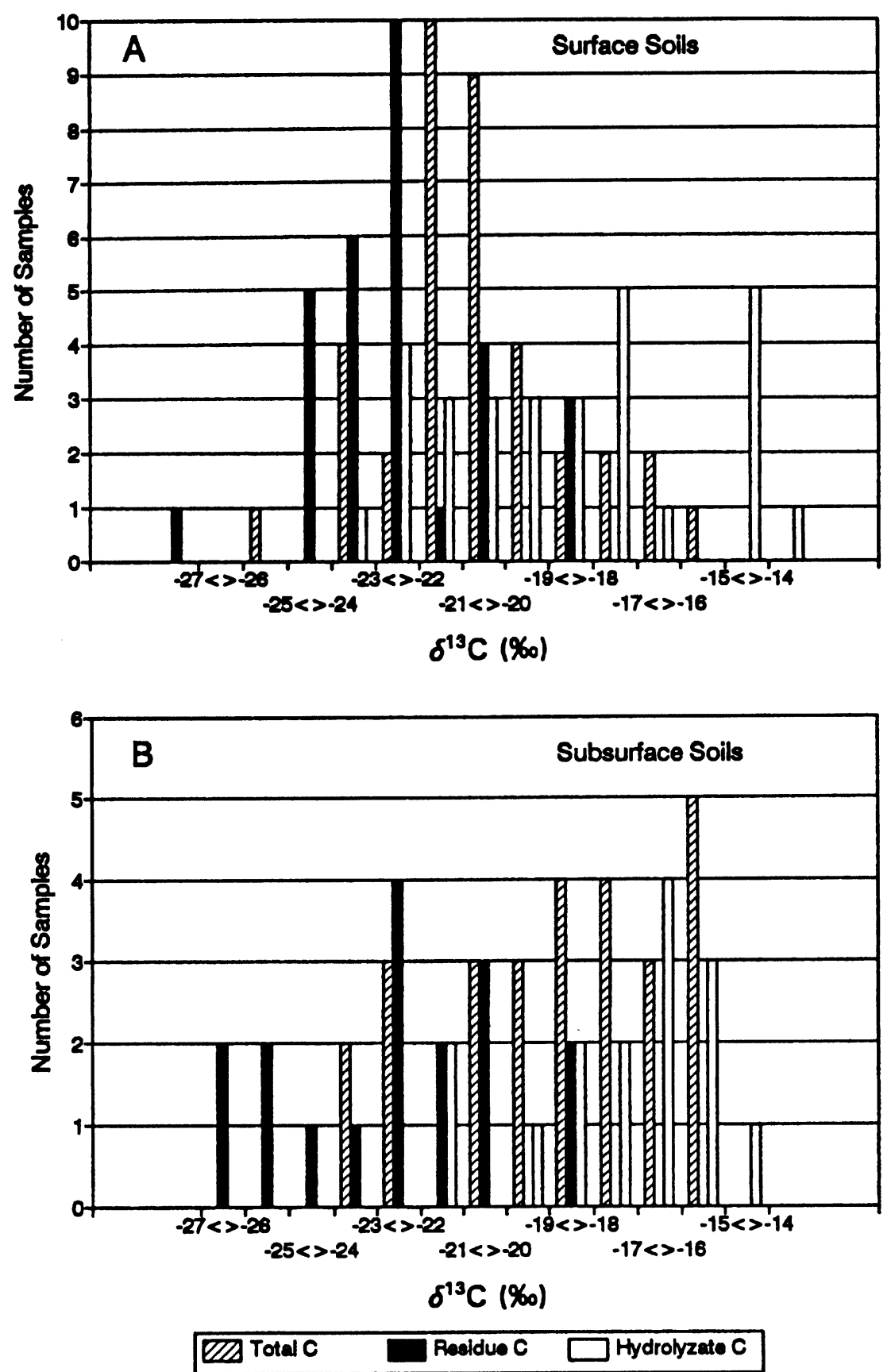

Fig. 2. Distribution of $\delta^{13} \mathrm{C}$ among soil organic carbon fractions of surface (A) and subsurface (B) soils. Symbols as in Fig. 1; $\square$ = acid-hydrolysis hydrolyzate. 
hydrolyzate for the subsurface soils, there is an implication that either an easily degradable form of carbon is being leached down into the subsurface, or a substantial amount of old carbon is converted into a form which may be recalcitrant but not with respect to $6 \mathrm{~N} \mathrm{HCl}$. If the latter were true, ${ }^{14} \mathrm{C}$ activity of the subsurface hydrolyzate fraction should be older than the hydrolyzate of the surface soils. Although we have no direct ${ }^{14} \mathrm{C}$ measurements of the hydrolyzate fraction of the subsurface soils, we infer from isotopic balance of the total carbon and residue ${ }^{14} \mathrm{C}$ that the hydrolyzate of the subsurface soils is indeed older than the surface hydrolyzate fraction by $c a .3500 \mathrm{yr}$, on average.

A more representative parameter than the average $\delta^{13} \mathrm{C}$ of fractions is the average isotopic difference between these fractions summarized in Table 1 . The greatest $\delta^{13} \mathrm{C}$ difference is indeed between the acid-hydrolysis residue and the hydrolyzate $(4.5 \pm 2.0 \%)$ for all soils, but the difference in subsurface soils is $c a$. 2\%o greater than in surface soils. Eight of the surface soils identified as virgin, uncultivated, had average $\delta^{13} \mathrm{C}$ differences between fractions that were within $0.4 \%$ of each of these overall average values. Thus, the consequences of cultivation do not seem to significantly alter this parameter.

Comparison of ${ }^{14} \mathrm{C}$ ages and $\delta^{13} \mathrm{C}$ with soil organic carbon content yielded no significant relationships. However, the $\delta^{13} \mathrm{C}$ of the total organic soil carbon, the residue fraction and the supernatant fraction were each inversely correlated to soil \% clay content (significance $P<0.01$ ). This may reflect a chance selection of the more clay-rich soils from sites associated with $\mathrm{C}_{3}$-type vegetation $\left({ }^{13} \mathrm{C}\right.$-depleted relative to $\mathrm{C}_{4}$-type vegetation). There was some evidence that the $\delta^{13} \mathrm{C}$ difference between organic fractions was smallest for soils with highest clay content, perhaps because organicmicrobial-clay interactions somehow promote greater stable-carbon isotope homogeneity of the organic fractions.

The tracer- ${ }^{14} \mathrm{C}$-contaminated soils represent an interesting demonstration with respect to the acid hydrolysis methods. If, indeed, the contamination did not occur at the University of Arizona but from field experimentation or from a laboratory or storage environment where dust associated with ${ }^{14} \mathrm{C}$ tracers might occur, we could verify the effectiveness of acid hydrolysis in removing this strong signal in whatever form it occurs. Two of the four surface soils that had ${ }^{14} \mathrm{C}$ activities in excess of $300 \mathrm{pMC}$ were acid-hydrolyzed. The ${ }^{14} \mathrm{C}$ ages of residues were $2900 \pm 50$ and $2300 \pm 50 \mathrm{BP}$. These are among the eight oldest residues (out of $29{ }^{14} \mathrm{C}$ measurements) from the surface soils. Unless these surface soils are really much older, the elevated ages of the residue suggest the tracer was in a soluble form that was effectively removed in the processing. Confirmation could be made by analyzing the ${ }^{14} \mathrm{C}$ content of the hydrolyzate fraction, but this has yet to be done. The form of this tracer may be very soluble in order for it not to be retained in the residue fraction.

The $6 \mathrm{~N} \mathrm{HCl}$ hydrolysis of the cotton plants resulted in $74 \%$ of the plant carbon ending up in the residue fraction (76 and $71 \%$ for the Arizona FACE experiment $\mathrm{CO}_{2}$-enriched and control samples, respectively). This suggests that the acid hydrolysis itself could be enhancing by a substantial amount the influence of recent carbon from plant residues on the residue pool. Numerous techniques have been used to separate the oldest soil carbon from recently added substrates, including humicfulvic fractionations, acid hydrolysis, separation of soil into various particle sizes and fractionation of intact soil aggregrates. No one technique can be expected to completely separate the fractions on an age basis because of differences in chemical recalcitrance, and the fact that much of the soil carbon is derived from microbial products that are protected from decomposition by physical as well as chemical stabilization (Paul and Clark 1989). The hydrolysis in $6 \mathrm{~N} \mathrm{HCl}$ has proven the simplest and most reproducible method for separating young from old carbon while giving meaningful separations of ${ }^{13} \mathrm{C}$ and ${ }^{14} \mathrm{C}$ in both field and laboratory experiments (Martel and Paul 1974). The primary 
limitation of hydrolysis of plant residue has been that lignin will remain in the non-hydrolyzable pool even though it is obviously not old material, and this is confirmed in our hydrolysis of cotton fragments. However, this effect may be minimized in our methods because all recognizable plant fragments were floated and picked from the soils prior to hydrolysis. Results from soils of the FACE project seem to support this contention: acid hydrolysis of soils from $\mathrm{CO}_{2}$-enriched plots, where ${ }^{14} \mathrm{C}$-depleted, newly added plant residue (depleted as a consequence of ${ }^{14} \mathrm{C}$-“dead" $\mathrm{CO}_{2}$ used to enrich the plots to $550 \mathrm{ppm}, c a .200 \mathrm{ppm}$ above ambient) would be expected to produce greater ${ }^{14} \mathrm{C}$ ages than plant matter of the control plots, did not show ${ }^{14} \mathrm{C}$ differences relative to the control plots (Leavitt et al. 1994).

\section{ConCLUSION}

Overall, our methods seem to be effective in separating younger, more easily decomposable carbon compounds from older, more recalcitrant carbon compounds. The ages of the acid-hydrolysis residue in all cases are older by an average of $1800 \mathrm{yr}$ relative to the total carbon pool, and the procedure is therefore isolating a relatively recalcitrant pool. This old residue fraction is $\mathrm{Ca} .2 .6 \%{ }^{13} \mathrm{C}$-depleted relative to total organic soil carbon, perhaps related to microbial effects. The floating and picking are effective in removing young carbon from the soil samples, without which substantial amounts of "young" carbon might make its way into the acid-hydrolysis residue fraction, as evidenced in the hydrolysis experiment with recent crop stubble. The dried masses and the isotopic composition of the floated and picked materials can also be determined to better define the pool of plant residue structural material.

\section{ACKNOWLEDGMENTS}

We thank B. Kimball, P. Pinter, G. Hendrey, H. L. Cho and R. Rauschkolb for assistance with the Maricopa FACE soil samples, and E. G. Preussner for Great Plains sample preparation. S. Haltead helped with Kellogg LTER samples. K. DeWitte, M. Farrell, N. Ferbiak, S. Danzer and others helped with sample preparation for stable-isotopic analysis, which was performed by B. McCaleb and T. Newberry in A. Long's Laboratory of Isotope Geochemistry. D. Donahue, T. Jull and L. Toolin among others at the NSF AMS Facility provided the ${ }^{14} \mathrm{C}$ analysis. Some of the Great Plains soil samples were from the archives at Mandan, North Dakota.

\section{REFERENCES}

Anderson, D. W. and Paul, E. A. 1984 Organo-mineral complexes and their study by radiocarbon dating. Soil Science Society of America Journal 48: 298-301.

Becker-Heidmann, P. and Scharpenseel, H. W. 1986 Thin layer $\delta^{13} \mathrm{C}$ and $\Delta^{14} \mathrm{C}$ monitoring of "Lessive" soil profiles. In Stuiver, M. and Kra, R., eds., Proceedings of the 12th International ${ }^{14} \mathrm{C}$ Conference. Radiocarbon 28(2A): 383-390.

Bertram, H. G. 1985 Zur Rolle des Bodens im globalen Kohlenstoffzyklus. Veröffentlichungen der Naturforschenden Gesellschaft zu Emden von 1814 8, Serie 3D3.

Boutton, T. W. 1991 Stable carbon isotope ratios of natural materials: I. Sample preparation and mass spectrometric analysis. In Coleman, D. C. and Fry, B., eds., Carbon Isotope Techniques. San Diego, Academic Press: 173-175.
Cambardella, C. A. and Elliott, E. T. 1992 Particulate soil organic-matter changes across a grassland cultivation sequence. Soil Science Society of America Journal 56: 777-783.

Campbell, C. A., Paul, E. A., Rennie, D. A. and McCallum, K. J. 1967 Factors affecting the accuracy of the carbon-dating method in soil humus studies. Soil Science 104: 81-85.

Dzurec, R. S., Boutton, T. W., Caldwell, N. M. and Smith, B. N. 1985 Carbon isotope ratios of soil organic matter and their use in assessing community composition changes in Carlew Valley, Utah. Oecologia 66: 17-24.

Follett, R. F., Paul, E. A., Leavitt, S. W., Halvorson, A. D., Lyon, D. and Peterson, G. A. (ms.) Determination of soil organic matter pool sizes and dynamics: Carbon- 13 contents of Great Plains soils and in wheat-fallow cropping systems. In preparation. 
Leavitt, S. W., Paul, E. A., Kimball, B. A., Hendrey, G. R., Mauney, J. R., Rauschkolb, R., Rogers, H., Lewin, K. F., Nagy, J., Pinter, P. J. and Johnson, H. B. 1994 Carbon isotope dynamics of free-air $\mathrm{CO}_{2}$-enriched cotton and soils. Agricultural and Forest Meteorology 70: 87-101.

Martel, Y. A. and Paul, E. A. 1974 The use of radiocarbon dating of organic matter in the study of soil genesis. Soil Science Society of America Proceedings 38: 501506.

Nissenbaum, A. and Schallinger, K. M. 1974 The distribution of the stable carbon isotope $\left({ }^{13} \mathrm{C} /{ }^{12} \mathrm{C}\right)$ in fractions of soil organic matter. Geoderma 11: 137-145.

Parton, W. J., Schimel, D. S., Cole, C. V. and Cole, D. S. 1987 Analysis of factors controlling soil organic matter levels in Great Plains grasslands. Soil Science Society of America Journal 51: 1173-1179.

Paul, E. A. and Clark, F. E. 1989 Soil Microbiology and Biochemistry. New York, Academic Press: 274 p.

Paul, E. A., Follett, R. F., Leavitt, S. W., Halvorson, A., Peterson, G. and Lyon, D. (ms.) Determination the pool sizes and dynamics of soil organic matter: Use of carbon dating for Great Plains soils. In preparation.

Scharpenseel, H. W. 1977 The search for biologically in- ert and lithogenic carbon in recent soil organic matter. In Proceedings of the Symposium on Soil Organic Matter Studies, Brunswick, FRG, September 1976, Vol. 2. Vienna, IAEA: 193-200.

Scharpenseel, H. W. and Schiffmann, H. 1977 Soil radiocarbon analysis and soil dating. Geophysical Surveys 3: $143-156$.

Schimel, D. S., Ojima, D. S., Holland, E. A. and Parton, W. J. 1993 Climatic and edaphic controls over carbon turnover in mineral soils: Simulations and validation (abstract). Bulletin of the Ecological Society of America 74(2) (Supplement): 427.

Slota, P. J., Jull, A. J. T., Linick, T. and Toolin, L. J. 1987 Preparation of small samples for ${ }^{14} \mathrm{C}$ accelerator targets by catalytic reduction of $\mathrm{CO}_{2}$. Radiocarbon 29(2): 303-306.

Stout, J. D., Goh, K. M. and Rafter, T. A. 1981 Chemistry and turnover of naturally occurring resistant organic compounds in soil. In Paul, E. A. and Ladd, J. N. Soil Biochemistry. Vol 5. New York, Marcel Dekker: 1-73.

Trumbore, S. E. 1993 Comparison of carbon dynamics in tropical and temperate soils using radiocarbon measurements. Global Biogeochemical Cycles 7: 275290. 